\title{
Treatment of Chronic Facial Erythema of Dermatomyositis with Intense Pulsed Light Therapy
}

Howard Chu

Do Young Kim

Department of Dermatology, Severance Hospital, Cutaneous Biology Research Institute, Yonsei University College of Medicine, Seoul, Korea
Received November 24, 2015

Revised November 30, 2015

Accepted November 30, 2015

\section{Correspondence}

Do Young Kim

Department of Dermatology and Cutaneous Biology Research Institute, Yonsei University College of Medicine, 50-1 Yonsei-ro, Seodaemungu, Seoul 03722, Korea

Tel: +82-2-2228-2080

Fax: +82-2-393-9157

E-mail: dykimayuhs.ac

(C) Korean Society for Laser Medicine and Surgery

(c) This is an open access article distributed under the terms of the Creative Commons Attribution NonCommercial License (http://creativecommons.org/ licenses/by-nc/4.0) which permits unrestricted noncommercial use, distribution, and reproduction in any medium, provided the original work is properly cited.
Dermatomyositis is an idiopathic inflammatory myopathy that may include persistent facial erythema, which is refractory to topical and systemic treatments. In previous reports a pulsed dye laser was effective in the treatment of these skin lesions. We report the first case of the use of intense pulsed light therapy for treatment of cutaneous lesions in dermatomyositis, which showed satisfactory results without aggravation of the disease activity or other complications.

\section{Key words}

Dermatomyositis; Intense pulsed light 


\section{INTRODUCTION}

Dermatomyositis (DM) is an idiopathic inflammatory myopathy characterized by typical cutaneous lesions, including Gottron's papules, periorbital violaceous or heliotrope rash, periungal telangiectasia, facial erythema and poikiloderma vasculare atrophicans. ${ }^{1}$ For the treatment of theses cutaneous lesions, topical steroids and topical calcineurin inhibitors are commonly used, while systemic agents such as glucocorticoids, antimalarials and methotrexate may be used in refractory cases. ${ }^{2}$ Despite all these treatments, cutaneous lesions may persist, causing severe impacts on patient's quality of life. To our knowledge, this is the first report of intense pulsed light (IPL) used in
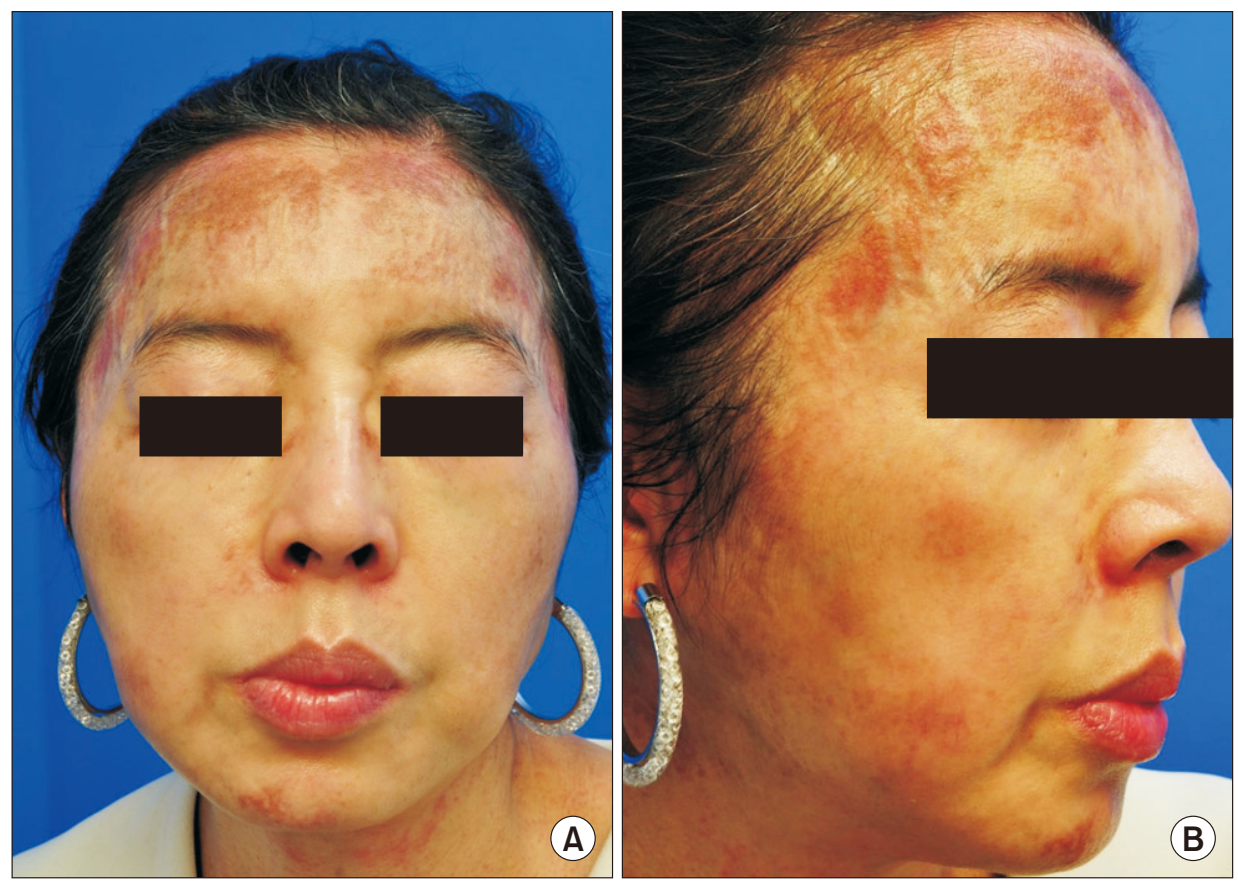

Fig. 1. Persistent erythema and hyperpigmentation is seen on the patient's forehead (A) and her right cheek (B).
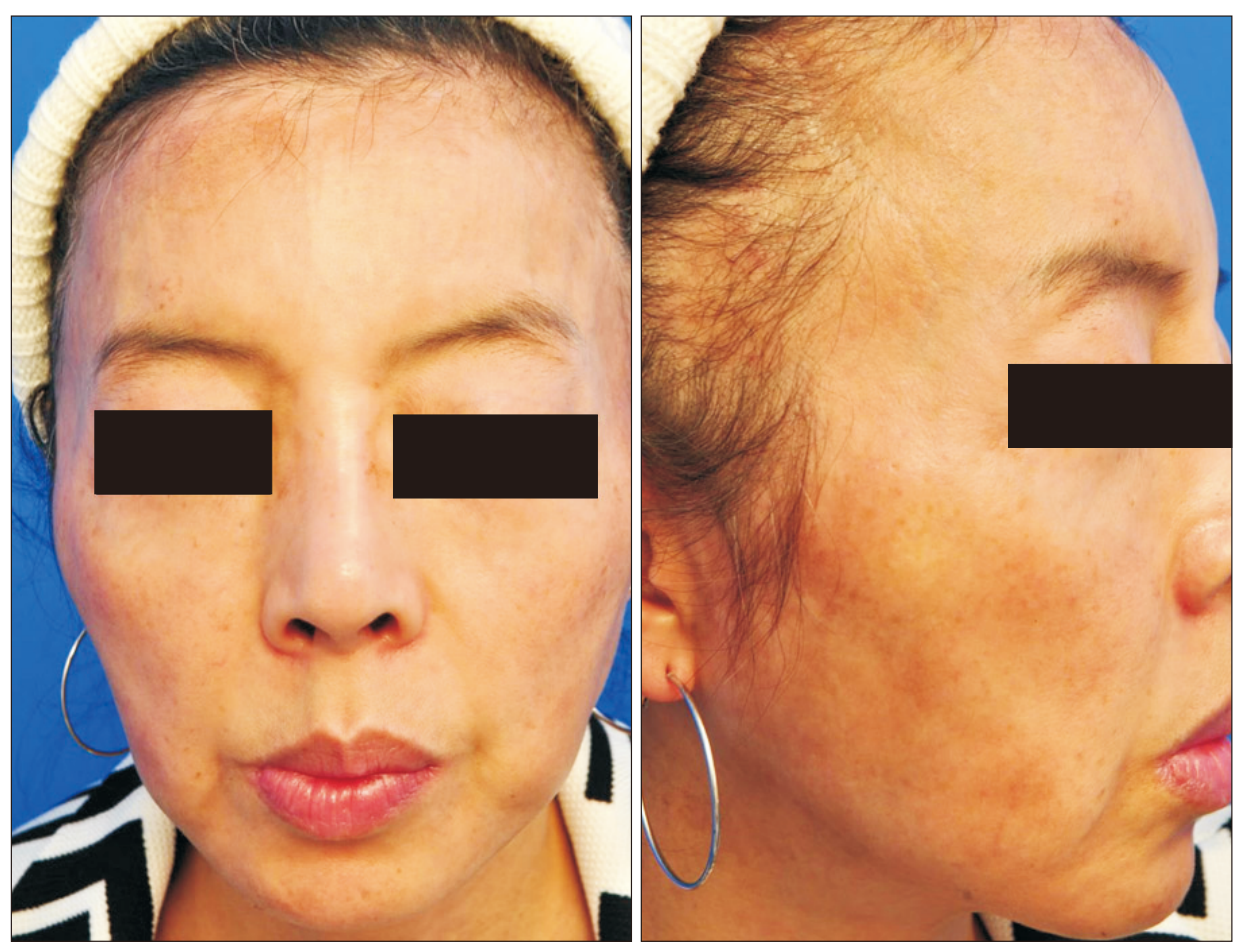

Fig. 2. Improvement of the skin lesions can be observed 6 months after the initial intense pulsed light (IPL) treatment. 5 sessions of IPL treatments have been done. 
the treatment of the persistent facial erythema in cutaneous dermatomyositis.

\section{CASE REPORT}

A 48-year-old female visited with skin lesions on her forehead, both cheeks, and hands. She was diagnosed with dermatomyositis 12 months prior to her visit to the dermatology clinic. Typical Gottron's papules were observed on her dorsums of both hands with persistent erythema and postinflammatory hyperpigmentation on her forehead, cheeks, and neck (Fig. 1). Her general symptoms were well-controlled with hydroxychloroquine, azathioprine, and low dose systemic steroid. Topical tacrolimus was also prescribed, but her cutaneous symptoms showed only minimal improvements. She was distressed with the redness on her face, which significantly affected her quality of life.

Treatment with IPL (BBL; Sciton Inc., CA, USA) was tried using 590-nm cutoff filter at a fluence $18-20 \mathrm{~J} / \mathrm{cm}^{2}$. Double pulse mode (two stacked 5 -ms pulses with a 20-ms delayl was selected. Significant improvements were observed with consecutive treatments and after six months, with a total five sessions of treatments, the patient was well-satisfied with the progresses (Fig. 2). The patient complained of only mild irritations after the treatments with no aggravation of the disease activity or any other severe complications were observed.

\section{DISCUSSION}

Due to the disfiguring skin changes in connective tissue diseases, the implications of laser therapies have been emerging. ${ }^{3}$ Table 1 lists the reports of the use of lasers in dermatomyositis. They have shown that pulsed dye laser and argon laser are efficacious in the treatment of erythema, poikiloderma, telangiectasia, and Gottron's papules in dermatomyositis. ${ }^{4-6}$ Although the use of IPL has not been applied to cutaneous dermatomyositis, it was reported to be effective in treating persistent erythema in lupus erythematosus. ${ }^{7}$

IPL emits high-intensity polychromatic light in a broad wavelength spectrum of 515-1,200 nm. Due to its wide spectrum, individual treatment parameters can be selected, adapting to different skin types and indications. Because of these characteristics of IPL, its use is indicated in the treatment of various skin lesions, including pigmented lesions, erythema, telangiectasia, and hair removal, 8,9 and its uses are becoming more diverse.

Regarding safety issue, there have been concerns 
about paradoxical worsening of lesions after exposure to lasers or light devices in these photosensitive disorders. However, a recent comprehensive review suggested no case reports have been published reporting the development or worsening of preexisting connective tissue disease after using lasers. ${ }^{3}$

To our best knowledge, this is the first report of the use of IPL in a patient with cutaneous dermatomyositis. IPL was found to an effective treatment method that did not interfere with the disease activity of dermatomyositis. Although more studies on its efficacy are required, IPL can be an effective and safe method of treatment for disfiguring skin changes in patients with dermatomyositis.

\section{REFERENCES}

1. laccarino L, Ghirardello A, Bettio S, Zen M, Gatto M, Punzi $L$, et al. The clinical features, diagnosis and classification of dermatomyositis. J Autoimmun 2014;48-49:122-7.

2. Lam C, Vleugels RA. Management of cutaneous dermatomyositis. Dermatol Ther 2012;25:112-34.
3. Brauer JA, Gordon Spratt EA, Geronemus RG. Laser therapy in the treatment of connective tissue diseases: a review. Dermatol Surg 2014;40:1-13.

4. Yanagi T, Sawamura D, Shibaki A, Shimizu H. Treatment for poikilodermatous erythema of dermatomyositis with the pulsed dye laser. Br J Dermatol 2005;153:862-4.

5. Calvo Pulido M, Boixeda De Miquel P, Martín Saez E, Fernandez Guarino M, García-Millán C. Treatment of Gottron papules of dermatomyositis with pulsed dye laser. Eur J Dermatol 2006;16:702-3.

6. Zachariae H, Bjerring P, Cramers M. Argon laser treatment of cutaneous vascular lesions in connective tissue diseases. Acta Derm Venereol 1988;68:179-82.

7. Levy JL. Intense pulsed light treatment for chronic facial erythema of systemic lupus erythematosus: a case report. J Cutan Laser Ther 2000;2:195-8.

8. Raulin C, Greve B, Grema H. IPL technology: a review. Lasers Surg Med 2003;32:78-87.

9. Babilas P, Schreml S, Szeimies RM, Landthaler M. Intense pulsed light (IPL): a review. Lasers Surg Med 2010;42:93-104. 